\title{
PECULIARITIES OF AEROBIC CAPACITY OF MILITARY ACADEMY STUDENTS
}

\author{
Arvydas Stasiulis ${ }^{1}$, Loreta Dubininkaitė ${ }^{1}$, Ronaldas Endrijaitis ${ }^{2}$, Arūnas Krasauskas ${ }^{2}$ \\ Lithuanian Academy of Physical Education ${ }^{1}$, Kaunas, \\ Lithuanian Military Academy², Vilnius, Lithuania
}

\begin{abstract}
Arvydas Stasiulis. Professor, Doctor of Biomedical Sciences, Head of Department of Applied Physiology and Health Education, Lithuanian Academy of Physical Education. The field of scientific research — aerobic performance's acute and chronic adaptation to the influence of training and laboratory loads.
\end{abstract}

\begin{abstract}
The aim of the study was to evaluate the aerobic capacity of the first year students in the Lithuanian Military Academy. 63 first year students (57 men and 6 women) agreed to participate in the study. They performed graded cycling exercise test until voluntary exhaustion. The starting work load was set at $70 \mathrm{~W}$ and was increased every minute by $21 \mathrm{~W}$. Pulmonary gas exchange was measured breath-by-breath using the portable telemetric system (Oxycon Mobile, Jaeger). The maximal oxygen uptake (VO, max) was determined as the highest $V \mathrm{O}_{2}$ within 20 s period obtained during increasing cycling test. Maximal cardiorespiratory values at this point were calculated as well. The VO, max in military academy cadets was 52.9 (4.6) $\mathrm{ml} / \mathrm{kg}^{-1} / \mathrm{min}^{-1}$ (from 42.7 to 63.4). The aerobic capacity in most cadets may be considered as high and very high (80\%), and only in one fifth of the subjects - as moderate, applying the normative scale for untrained persons.
\end{abstract}

Keywords: maximal oxygen uptake, aerobic capacity, cycling ergometry.

\section{INTRODUCTION}

$\mathrm{A}$ erobic capacity is defined as the ability to perform long and intensive work by means of dominating aerobic ATP production in working muscles. This capacity is characterized by maximal oxygen consumption $\left(\mathrm{VO}_{2} \max \right)$ and anaerobic thresholds as well as work economy and rate of rest to work transitions (Jones, Carter, 2000). $\mathrm{VO}_{2} \max$ is dependent on the maximal rate of aerobic ATP production and oxygen transport capacity by cardiorespiratory system (Astrand, 1952). It is usually determined during graded exercise test by measuring pulmonary gas exchange parameters (Duncan et al., 1997).
The highest values of $\mathrm{VO}_{2} \max$ (above $80 \mathrm{ml} /$ $\mathrm{kg}^{-1} / \mathrm{min}^{-1}$ ) have been recorded in endurance athletes such as cyclists, distance runners, skiers, rowers and swimmers. The $\mathrm{VO}_{2}$ max was shown to be lower in other athletes and in untrained subjects reaching only $40 \mathrm{ml} / \mathrm{kg}^{-1} / \mathrm{min}^{-1}$ and $35 \mathrm{ml} / \mathrm{kg}^{-1} / \mathrm{min}^{-1}$ in men and women respectively (Neumann, 1988). The $\mathrm{VO}_{2} \max$ is important not only for athletes but also for moderately active persons because it reflects the general ability of the organism to adapt to physical and even other kinds of activity. Aerobic capacity is known to influence positively the 
recovery of muscular power, phosphocreatine and blood lactate disappearing (Tomlin, Wenger, 2001 ), it is associated with the risk of trauma or illness in soldiers and cadets (Harwood et al., 1999; Knapik et al., 2001). The data about influence of aerobic capacity on heat tolerance (Selkirk, Mc Lellan, 2001), sleep quality (Shapiro et al., 1984), personality characteristics (Jasnoski et al., 1988), stability of reaction time during exercise (Brisswalter et al., 1997) are also available. Since $\mathrm{VO}_{2}$ max depends on physical activity level, changes under influence of endurance training, it may also reflect the effectiveness of soldiers or cadets physical education programmes (Vogel et al., 1986).

The aim of this study was to evaluate the aerobic capacity in the Lithuanian Military Academy's first year students.

\section{METHODS}

Subjects. 63 Lithuanian Military Academy's first year students (57 men and 6 women) agreed to participate in the study. Their age and anthropometric characteristics are presented in Table 1.

Graded exercise test, data collection and $\mathrm{VO}_{2}$ max determination were the methods of the survey.

All subjects performed a maximal incremental test on the cycle ergometer Monark 834E. Before the test a 5 min warm up with the intensity of $70 \mathrm{~W}$ was performed. The incremental test consisted of each minute increasing cycling with pedalling frequency $70 \mathrm{rpm}$. Starting workload was $70 \mathrm{~W}$, the increase at each step - $21 \mathrm{~W}$. All subjects were encouraged to continue as long as they were able to maintain the required pedalling frequency. After that the subjects rested for five minutes in the supine position.

Pulmonary gas exchange was measured breathby-breath using the portable telemetric system (Oxycon Mobile, Jaeger). The flow-volume sensor and the gas analyser (gas mixtures containing 5\% $\mathrm{CO}_{2}$ and $16 \% \mathrm{O}_{2}$ were used) were calibrated using automatic calibration procedures, as provided by Jaeger, before each testing session. Data on gas exchange were averaged over $5 \mathrm{~s}$ intervals. Heart rate was recorded simultaneously (Polar S 810, Electro, Finland). The maximal oxygen uptake $\left(\mathrm{VO}_{2} \max \right)$ was determined as the highest $\mathrm{VO}_{2}$ within $20 \mathrm{~s}$ period obtained during increasing cycling test (Fig. 1). Maximal cardiorespiratory values at this point were calculated as well.

Capillary blood samples from a finger tip were analysed for lactate concentration with an aid of Exan-G lactate analyser (Kulis et al., 1988). The blood samples were taken after five mins of the supine rest following graded exercise test.

Statistical analysis. The mean values, standard

\begin{tabular}{|l|c|c|c|}
\hline Academic group & Age, years & Height, cm & Body mass, kg \\
\hline $1(\mathrm{n}=12)$ & $19.8(1.2)$ & $182.4(10.2)$ & $79.0(11.7)$ \\
\hline $2(\mathrm{n}=15)$ & $19.5(0.5)$ & $184.5(7.3)$ & $80.2(9.1)$ \\
\hline $3(\mathrm{n}=15)$ & $19.1(0.4)$ & $181.9(4.3)$ & $77.3(7.1)$ \\
\hline $4(\mathrm{n}=15)$ & $19.6(0.6)$ & $180.0(6.7)$ & $77.1(5.8)$ \\
\hline Women $(\mathrm{n}=6)$ & $19.2(0.8)$ & $167.2(6.6)$ & $64.0(4.4)$ \\
\hline
\end{tabular}

Table 1. The age and anthropometric characteristics of the subjects in different academic groups and women students, mean (SD)

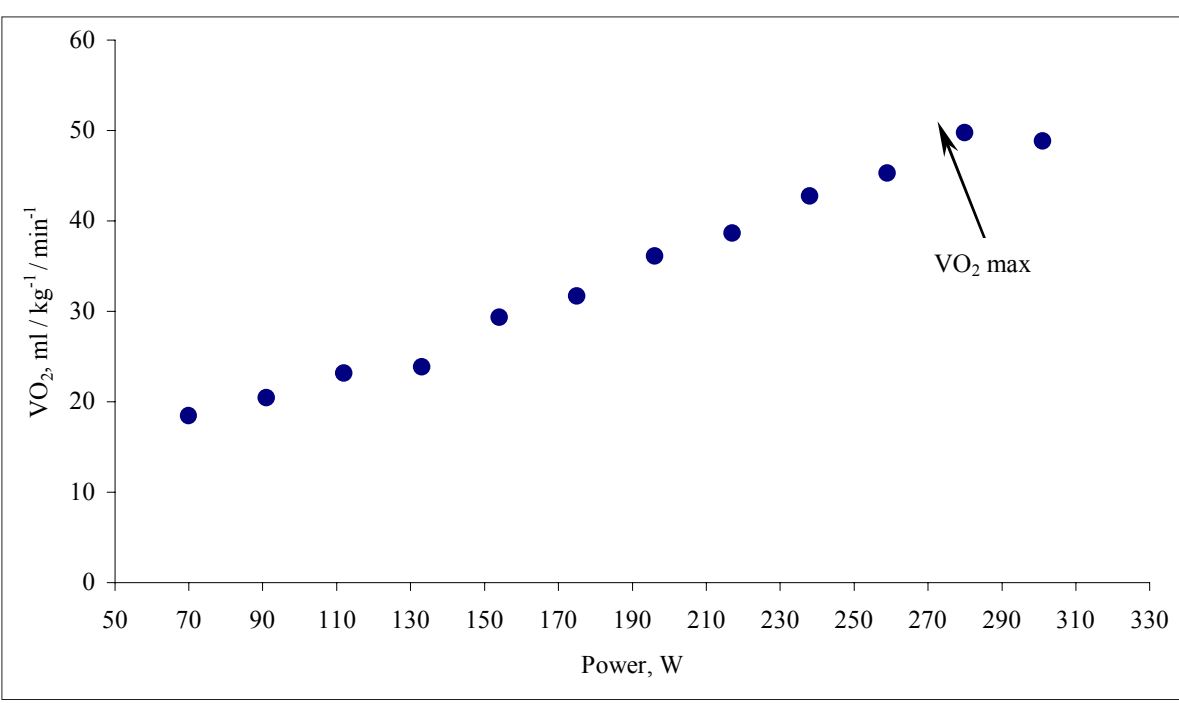

Fig. 1. Determination of $\mathrm{VO}_{2}$ max. $\mathrm{VO}_{2}$ max was determined as the highest $\mathrm{VO}_{2}$ within $20 \mathrm{~s}$ period obtained during increasing cycling test 
deviations, maximal and minimal values, 95\% confidence intervals were calculated. The means were compared using Student's T-test for unpaired data. $\mathrm{P}$ values less then 0.05 were considered as statistically significant.

\section{RESULTS}

All absolute and relative (expressed as $\mathrm{ml}$ per $\mathrm{kg}$ of body weight) values of $\mathrm{VO}_{2} \max$ in cadets investigated are presented in Table 2, while the means of this parameter in different academic groups and in women subjects are shown in Fig. 2. Only in the second group $\mathrm{VO}_{2} \max$ was significantly higher, but in other groups including that of women it was very similar. The distribution of aerobic capacity level according to the scale for untrained persons are presented in Fig. 3. Aerobic capacity in students can be considered as moderate $(19.3 \%)$, high $(42.1 \%)$ or very high $(38.6 \%)$.

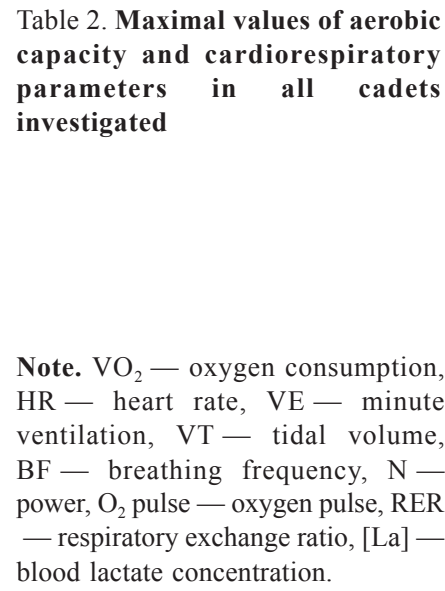

Table 2. Maximal values of aerobic capacity and cardiorespiratory parameters in all cadets investigated

Note. $\mathrm{VO}_{2}$ - oxygen consumption $\mathrm{HR}$ - heart rate, VE - minut ventilation, VT - tidal volume, $\mathrm{BF}$ - breathing frequency, $\mathrm{N}$ power, $\mathrm{O}_{2}$ pulse - oxygen pulse, RER - respiratory exchange ratio, [La] blood lactate concentration.

\begin{tabular}{|l|c|c|c|c|c|}
\hline Indices & Mean & $\begin{array}{c}\text { Standard } \\
\text { deviation }\end{array}$ & $\begin{array}{c}\text { Minimal } \\
\text { value }\end{array}$ & $\begin{array}{c}\text { Maximal } \\
\text { value }\end{array}$ & $\begin{array}{c}95 \% \\
\text { confidence } \\
\text { interval }\end{array}$ \\
\hline $\mathrm{VO}_{2} \mathrm{max}, 1 / \mathrm{min}^{-1}$ & 4.132 & 0.460 & 3.202 & 5.151 & 0.120 \\
\hline $\mathrm{VO}_{2} \mathrm{max}, \mathrm{ml} / \mathrm{kg}^{-1} / \mathrm{min}^{-1}$ & 52.9 & 4.6 & 42.7 & 63.4 & 1.2 \\
\hline $\mathrm{HR} \max$, beats $/ \mathrm{min}^{-1}$ & 188.1 & 8.0 & 170.0 & 204.0 & 2.09 \\
\hline $\mathrm{VE} \max , 1 / \mathrm{min}^{-1}$ & 150.3 & 23.4 & 105.0 & 213.3 & 6.13 \\
\hline $\mathrm{VT} \max , 1$ & 3.171 & 0.489 & 2.416 & 4.113 & 0.128 \\
\hline $\mathrm{BF} \max , 1 / \mathrm{min}^{-1}$ & 49.7 & 8.4 & 33.7 & 69.3 & 2.19 \\
\hline $\mathrm{N} \max , \mathrm{W}$ & 327.6 & 29.6 & 259.0 & 385.0 & 7.75 \\
\hline $\mathrm{O}_{2}$ pulse & 22.1 & 2.5 & 17.7 & 27.4 & 0.65 \\
\hline $\mathrm{RER} \max$ & 1.215 & 0.016 & 1.073 & 1.397 & 0.016 \\
\hline$[\mathrm{La}]$ at $5^{\text {th }} \min$ of recovery, $\mathrm{mmol} / \mathrm{l}^{-1}$ & 6.99 & 1.80 & 3.00 & 10.90 & 0.47 \\
\hline
\end{tabular}

Fig. 2. The comparison of $\mathrm{VO}_{2}$ max values (means and SD) among academic and women subjects groups

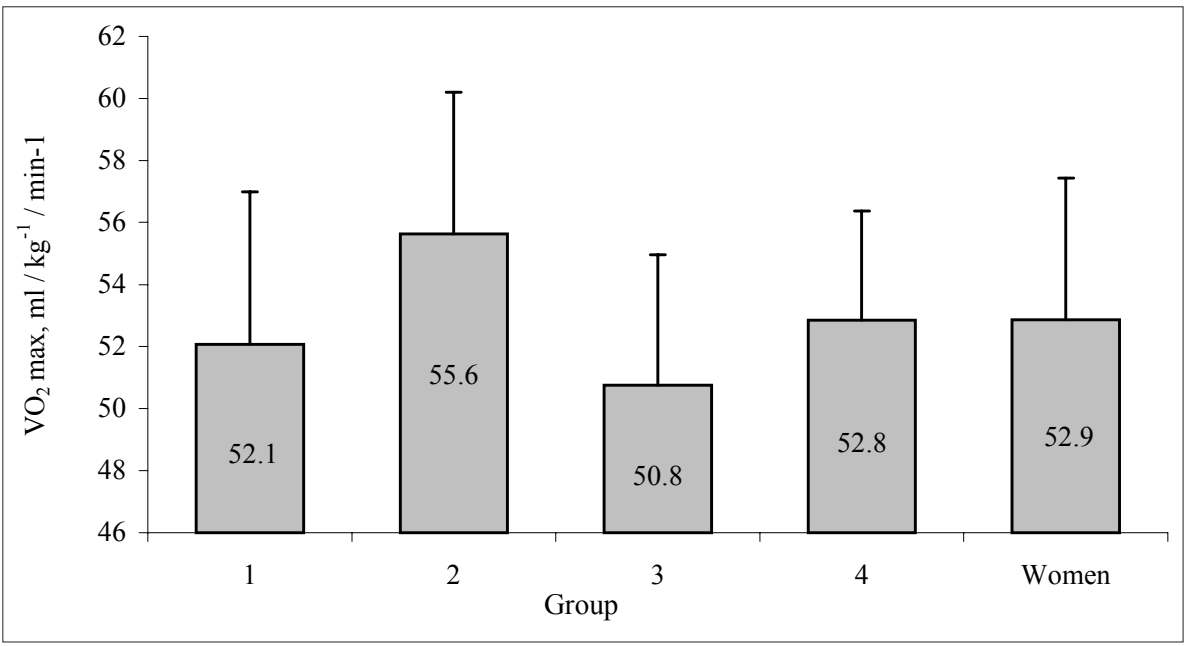

Fig. 3. Distribution of aerobic capacity level in cadets investigated (according to American Heart Association standards)

Note. Margins of aerobic capacity levels: $<33 \mathrm{ml} / \mathrm{kg}^{-1} / \mathrm{min}^{-1}$ — very low; $33-38 \mathrm{ml} / \mathrm{kg}^{-1} / \mathrm{min}^{-1}-$ low; 39-48 $\mathrm{ml} / \mathrm{kg}^{-1} / \mathrm{min}^{-1}$ — moderate; $49-54 \mathrm{ml} / \mathrm{kg}^{-1} / \mathrm{min}^{-1}$ — high; $>55 \mathrm{ml} / \mathrm{kg}^{-1} / \mathrm{min}^{-1}$ — very high.

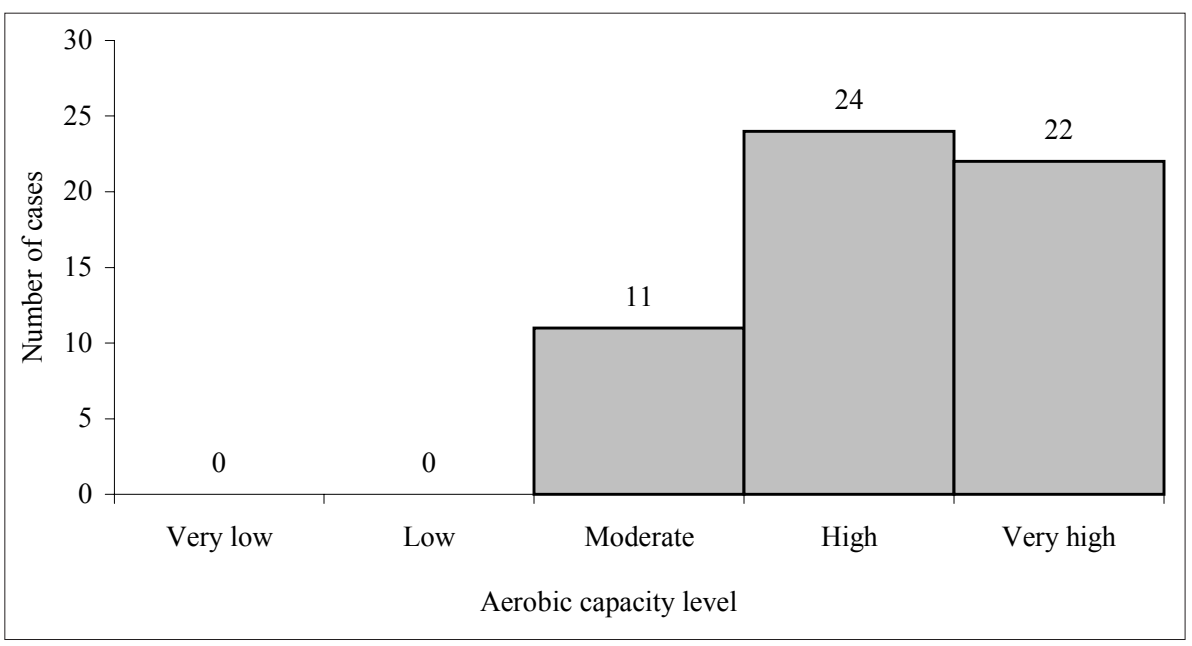




\section{DISCUSSION}

In this study the aerobic capacity and maximal cardiorespiratory values of Military Academy's students were determined by means of graded cycle ergometer test. The aerobic capacity in most cadets may be considered as high and very high $(80 \%)$, and only in one fifth of the subjects - as moderate, applying the normative scale for untrained persons.

The maximal values of heart rate (HR), minute ventilation and respiratory exchange ratio (RER) reached at the and of graded exercise test show the adequate motivation of the subjects and may be an evidence that true maximal aerobic capacity $\left(\mathrm{VO}_{2} \max \right)$ values were measured in this investigation. The most acceptable criterion that the subject reached his true $\mathrm{VO}_{2}$ max is the plato in oxygen consumption and power relationship. This is the case only for $50 \%$ of the subjects (Astrand, 1952). We observed plato only in 35\% of the subjects. Therefore the decision about true $\mathrm{VO}_{2}$ max achievement by the subject is often made according to such indirect criterions as blood lactate concentration which during the first five minutes of recovery should be higher than $8 \mathrm{mmol} / \mathrm{l}^{-1}$, RER and HR at the end of test which should be higher than 1.1 and $85 \%$ of age predicted maximum, respectively (Astrand, 1952; Issekutz et al., 1962). In our case only blood lactate concentration at the fifth min of recovery was lower than $8 \mathrm{mmol} / \mathrm{l}^{-1}$, but maximal values of RER and HR exceeded required values.

The $\mathrm{VO}_{2}$ max values measured in our study are similar to those of cadets in other countries. $\mathrm{VO}_{2}$ max of New Zeeland's soldiers was reported to be $50.8(6.2) \mathrm{ml} / \mathrm{kg}^{-1} / \mathrm{min}^{-1}$, with interval from 39.8 to $66.0 \mathrm{ml} / \mathrm{kg}^{-1} / \mathrm{min}^{-1}$ (O'Donnell et al., 1984). The USA army recruits demonstrated such $\mathrm{VO}_{2}$ max during treadmill exercise test: men - 50.6 (6.2): women - 39.7 (5.2) (Sharp et al., 2002). So, our Military Academy's female students demonstrated rather higher aerobic capacity. The results of many investigations demonstrate that soldiers and cadets need higher than moderate aerobic capacity level. This may be associated with purposeful training programmes used in many military institutions. As established by the USA investigators, the $\mathrm{VO}_{2}$ max among the USA army recruits was increased by $5 \%$ after the initial basics physical training period (Vogel et al., 1986). Obviously, the possible influence of other factors on $\mathrm{VO}_{2} \max$ cannot be ignored. For example, $\mathrm{VO}_{2}$ max is strongly dependent on the genetic factors (Jones, Carter, 2000). This might be the important reason for $\mathrm{VO}_{2}$ max variation among subjects or academic groups observed in our study.

It is widely accepted that $\mathrm{VO}_{2}$ max is one of the most important indexes of human physical readiness, especially that of aerobic endurance (Jones, Carter, 2000). There are strong evidences that $\mathrm{VO}_{2}$ max is limited by maximal cardiac output, blood oxygen carrying capacity and sometimes pulmonary system in the population of healthy people performing dynamic exercise with involvement of large muscle groups (Cerretelli, Di Prampero, 1987; Richardson, Saltin, 1998). What may be the role of $\mathrm{VO}_{2}$ max for soldiers or cadets? It was established that recovery after intensive exercise is slower among the subjects with low aerobic capacity (Hoffman, 1997). The heat tolerance is higher (Selkirk, McLellan, 2001), the slowdown of reaction during fatigue is less (Brisswalter et al., 1997) and the risk of trauma is lower (Harwood et al., 1999) among persons with higher aerobic capacity level. All the mentioned above factors are closely related to the quality of the soldier or cadet professional activity. So, the testing of aerobic capacity in the military population seems to be important for evaluation of their professional readiness and effectiveness of physical training programs.

\section{CONCLUSIONS}

The $\mathrm{VO}_{2}$ max in Military Academy's cadets is 52.9 (4.6) $\mathrm{ml} / \mathrm{kg}^{-1} / \mathrm{min}^{-1}$ (from 42.7 to 63.4). The aerobic capacity in most cadets may be considered as high and very high (80\%), and only in one fifth of the subjects - as moderate, applying the normative scale for untrained persons. 


\section{REFERENCES}

Astrand, P. O. (1952). Experimental Studies of Physical Working Capacity in Relation to Sex and Age. Copenhagen: Ejnar Munksgaard. P. 23-27.

Brisswalter, J., Arcelin, R., Audiffren, M., Delignieres, D. (1997). Influence of physical exercise on simple reaction time: Effect of physical fitness. Perceptual Motor Skills, 85 (3 Pt. 1), 1019-1027.

Cerretelli, P., Di Prampero, P. E. (1987). Gas exchange in exercise. In A. P. Fishman, L. E. Farhi, S. M. Tenney, S. R. Geiger (Eds.), Hanbook of Physiology. Bethesda, MD: American Physiological Society. P. 297-339.

Duncan, G., Howley, E., Johnson, B. (1997). Applicability of $\mathrm{VO}_{2}$ max criteria: discontinuous versus continuous protocols. Medicine \& Science in Sports \& Exercise, 29, $273-278$.

Exercise standards: A statement for health professionals form the American Heart Association. (1990). Circulation, $82,2286-2322$.

Harwood, G. E., Rayson, M. P., Nevill, A. M. (1999). Fitness, performance, and risk of injury in British Army officer cadets. Military Medicine, 164 (6), 428-434.

Hoffman, J. R. (1997). The relationship between aerobic fitness and recovery from high-intensity exercise in infantry soldiers. Military Medicine, 162 (7), 484-488.

Issekutz, B., Birkhead, N., Rodahl, K. (1962). The use of respiratory quotients in assessment of aerobic power capacity. Journal of Applied Physiology, 17, 47-50.

Jasnoski, M. L., Holmes, D. S., Banks, D. L. (1988). Changes in personality associated with changes in aerobic and anaerobic fitness in women and men. Journal of Psychosomatic Research, 32 (3), 273-276.

Jones, A., Carter, H. (2000). The effect of endurance training on parameters of aerobic fitness. Journal of Sports Medicine, 29, 373-386.

Knapik, J. J., Sharp, M. A., Canham-Chervak, M., Hauret, K., Patton, J. F., Jones, B. H. (2001). Risk factors for training-related injuries among men and women in basic combat training. Medicine \& Science in Sports \& Exercise, 33 (6), 946-954.
Kulis, Y. Y., Laurinavichyus, V. S. A., Firantas, S. G. A., Kurtinaitiene, B. S. (1988). Determination of lactic acid with an Exan-G analyser. Journal of Analytical Chemistry of the USSR, 43(7), 1521-1523.

Neumann, G. (1988). Special performance capacity. In A. Dirix, H. G. Knuttgen, K. Tittel (Eds.), The Olympic Book of Sports Medicine, 1, 97-108.

O’Donnell, C., Smith, D. A., O’Donnell, T. V., Stacy, R. J. (1984). Physical fitness of New Zealand army personnel; correlation between field tests and direct laboratory assessments-anaerobic threshold and maximum $\mathrm{O}_{2}$ uptake. New Zeland Medical Journal, 97 (760), 476-479.

Richardson, R., Saltin, B. (1998). Human muscle blood flow and metabolism studied in the isolated quadriceps muscles. Medicine \& Science in Sports \& Exercise, 30 (1), $28-33$.

Selkirk, G. A., McLellan, T. M. (2001). Influence of aerobic fitness and body fatness on tolerance to uncompensable heat stress. Journal of Applied Physiology, 91 (5), 2055-2063.

Shapiro, C. M., Warren, P. M., Trinder, J., Paxton, S. J., Oswald, I., Flenley, D. C., Catterall, J. R. (1984). Fitness facilitates sleep. European Journal of Applied Physiology and Occupational Physiology, 53 (1), 1-4.

Sharp, M. A., Patton, J. F., Knapik, J. J., Hauret, K., Mello, R. P., Ito, M., Frykman, P. N. (2002). Comparison of the physical fitness of men and women entering the U. S. Army: 1978 - 1998. Medicine \& Science in Sports \& Exercise, 34 (2), 356-363.

Tomlin, D. L., Wenger, H. A. (2001). The relationship between aerobic fitness and recovery from high intensity intermittent exercise. Sports Medicine, 31 (1), 1-11.

Vogel, J. A., Patton, J. F., Mello, R. P., Daniels, W. L. (1986). An analysis of aerobic capacity in a large United States population. Journal of Applied Physiology, 60 (2), 494-500.

\author{
Arvydas Stasiulis \\ Lithuanian Academy of Physical Education \\ Sporto str. 6, LT-44221 Kaunas \\ Lithuania \\ Tel +37037302671 \\ E-mail a.stasiulis@1kka.1t
}

